\title{
Effects of water exposure on bitumen surface microstructure
}

\author{
Albert M. Hung, ${ }^{\mathrm{a},}$ Adrian Goodwin, ${ }^{\mathrm{a}}$ Elham H. Fini ${ }^{\mathrm{b}}$ \\ * Corresponding author. Tel.: 336-285-3676; fax: 336-344-7126; e-mail: efini@ @ncat.edu \\ a. Innovation Center for Materials, Method and Management, North Carolina A\&T State University, 2907 E. Gate \\ City Blvd., Greensboro, NC 27401, USA \\ b. Department of Civil, Architectural and Environmental Engineering, North Carolina A\&T State University, 1601 \\ E. Market St., Greensboro, NC 27411, USA
}

\begin{abstract}
In applications such as asphalt pavement and roofing shingles, bituminous binder not only binds aggregate structure together but also acts as a waterproof sealant. However, moisture can still diffuse into the binder over time, reducing binder adhesion to aggregate or causing other changes that increase asphalt susceptibility to further water damage. Accordingly, this paper investigates the effects of water exposure at elevated temperature or extended duration on bituminous asphalt binder. Atomic force microscopy (AFM) images of bitumen samples exposed to water at ambient temperature showed "nano-bumps" appearing on characteristic "bee" structures on the bitumen surface, and Fourier transform infrared spectroscopy (FTIR) showed an enrichment of polar compounds at the surface due to water exposure. The nano-bumps are hypothesized to be para phase resin absorbing water and seeping up from underneath the "bee" structure through pinhole defects. At elevated temperature under water, the chemical and structural evolution accelerated, and new "aqueous peri phase" features appeared on the surface that were similar to but independent of the original "bee" structures. The results are important for furthering understanding of the aging process in bitumen under environmental exposure and the relation between composition and performance properties.
\end{abstract}

Keywords: Asphalt; bitumen; moisture; temperature; atomic force microscopy; FTIR; "bee" structure; wax

\section{Introduction}

(C) 2017. This manuscript version is made available under the Elsevier user license http://www.elsevier.com/open-access/userlicense/1.0/ 
The enormous scale and associated cost of repairing and refurbishing the nation's transportation infrastructure and the persistent environmental and political concerns over the use and acquisition of petroleum resources has spurred interest in developing and qualifying new asphalt mixtures as well as more effective processing of recycled asphalt pavement. To facilitate and enable such efforts, fundamental understanding of the nanoscale structure and properties of asphalt binder as well as unveiling how these properties change with age and environmental exposure is critical. This knowledge in turn would enable development of methods and processes to mitigate or reverse those unwanted changes. Water exposure is a particular concern for material aging and performance in different environments. Moisture damage degrades the mechanical and adhesive properties of asphalt concrete and binder [1-5], but the molecular mechanisms by which this damage occurs are not well understood. Each of the various hydrocarbon constituents of bituminous asphalt binder may interact with each other and with water differently. Furthermore, new additives used to improve the mechanical properties or workability of binders may alter the material response to moisture [6-9].

An important consideration for understanding the bitumen aging process is the fact that the structure and composition of bitumen may not be the same even a few micrometers within the bitumen film as at the bitumen-air surface where environmental factors would have the greatest impact. The surfaces of some binders show undulating topological features that appear bee-like when imaged by atomic force microscope (AFM) [10,11]. Recent studies suggest that these "bee" structures are crystallized wax lamellae as thin as $10 \mathrm{~nm}$ and that the topological undulations arise from buckling of this film under compressive strain [12-16]. The "bees" may grow [17-23] or shrink [24, 25] depending on bitumen type and aging process, and "bee" length can have a moderating effect on the relationship between viscosity, stiffness, and fracture properties of bitumen [22]. As such, studying the evolution of the "bee" structures due to aging and environmental conditions is instrumental to elucidate their impact on bitumen long-term performance.

Saturates and waxes are less polar and less inclined to associate with water than asphaltenes or resins. Thus, waxy "bees" at the bitumen surface could naturally inhibit water diffusion. However, studies 
show that the surface microstructure changes significantly when bitumen is exposed to water [26, 27]. Dos Santos et al. reported nano-bumps appearing on the "bees" after four hours of immersion [26]. The "bee" valleys were also flooded with softer material that presumably seeped up from underneath the wax film through stress-induced cracks. Vasconcelos et al. also measured an increase in water diffusivity with repeated exposure which they attributed to retention of absorbed water in the material and alteration of the surface microstructure $[27,28]$.

A better understanding of how and why water changes the bitumen surface microstructure and chemistry is necessary for new material development and predicting material behavior in aqueous environments. In this paper, the effects of water exposure on a sample of bituminous asphalt binder are studied by AFM and Fourier transform infrared spectroscopy (FTIR). Conditions of elevated temperature or extended exposure time resulted in the appearance of novel surface features as well as an enrichment of polar compounds at the surface. These observations provide insight into the relationship between chemistry, microstructure, and macroscale properties of bitumen.

\section{Materials and methods}

The bitumen used in this study was PG 64-22, a binder grade commonly used in the United States and acquired from Associated Asphalt Inc. (http://associatedasphalt.com). Physical and chemical properties of this binder were reported elsewhere [12]. A typical sample consisted of 15-25 mg of bitumen deposited cold onto a 0.5 " square glass slide that was pre-cleaned by sequential ultrasonication in acetone, isopropanol, and deionized (DI) water. All samples were annealed at $150{ }^{\circ} \mathrm{C}$ for 30 min and then allowed to cool to room temperature and equilibrate for at least one day before any further treatment or characterization.

Bitumen samples on glass slides were exposed to water by immersing them in $3 \mathrm{~mL}$ DI water in a capped glass vial. Surfaces and lab utensils were frequently cleaned with isopropanol to reduce the risk of microbial growth on the bitumen. To test the effects of elevated temperature, the water vial was first preheated in a hot water bath at $35-80{ }^{\circ} \mathrm{C}$. A thermocouple inserted through a hole drilled through the cap 
of the vial was used to directly monitor the temperature of the water in the vial (see ESI Figure S1). The bitumen sample was placed in the warm water vial, and the vial was tightly capped and returned to the hot water bath. After $1 \mathrm{~h}$ under heating, the vial was transferred to a room temperature water bath for 5 min to cool below at least $25^{\circ} \mathrm{C}$. Even the room temperature sample was subjected to the $5 \mathrm{~min}$ "cooling period" in order to keep the total time in water consistent. The bitumen sample was then removed from the water, briefly dried with a nitrogen gun, and imaged by AFM. See ESI Figure S2 for the cooling curves of each sample. After imaging, the sample was returned to the warm water vial for another $3 \mathrm{~h}$ before cooling and imaging again. Note that the " $1 \mathrm{hr}$ " and " $4 \mathrm{hr}$ " exposure times refer to the cumulative time at the set temperature in water and doesn't include the cooling time. To test the effect of slow cooling, one sample was immersed in $65^{\circ} \mathrm{C}$ water for $1 \mathrm{~h}$ before the hotplate was turned off. The vial was kept in the hot water bath for $1.3 \mathrm{~h}$ as the whole bath cooled to $25^{\circ} \mathrm{C}$. To test the effect of $100 \%$ humidity at room temperature, a bitumen sample was stored for several days in a tightly capped jar with a water-moistened wad of laboratory tissue paper (ensure that the sample and paper do not touch) and periodically taken out of the jar for AFM imaging.

AFM imaging was performed with a large stage 5600LS AFM (Keysight Technologies) in tapping mode with TAP-300 silicon cantilever tips (Budget Sensors, 40 N/m nominal spring constant, $300 \mathrm{kHz}$ nominal frequency). Images were processed and analyzed with Gwyddion open-source software. FTIR in attenuated total reflectance mode (ATR-FTIR) was performed on a Cary 670 FTIR (Agilent Technologies) using a diamond ATR crystal and $45^{\circ}$ reflection angle. After AFM imaging, the bitumen samples were kept intact, and the exposed sample surface was pressed directly in contact with the ATR crystal. For this configuration, the penetration depth of the infrared radiation into the sample is typically $0.5-3.0 \mu \mathrm{m}$ depending on wavenumber and sample refractive index [29].

\section{Results and discussion}




\subsection{Effect of water exposure time and temperature on morphology}

AFM images of bitumen before and after water immersion at room temperature over 10 days are shown in Figure 1. The "bees" are visible as elongated features with periodic undulating hills and valleys that appear as light and dark stripes in AFM images. This region is referred to as the catana phase, and it is surrounded by a flat peri phase area that is itself surrounded by a mechanically distinct para phase [30]. After $1 \mathrm{~h}$ in water at room temperature, nano-bumps were observed on the peri and catana phases. These features are consistent with previous results [26]. Note that in the valleys of the catana phase, the nanobumps did not fill the valley but were significantly larger than in other areas. After $4 \mathrm{~h}$ at room temperature, the catana phase valleys were flooded and the nano-bumps grew and began to merge with their neighbors. Over the course of 10 days, the nano-bumps continued to grow and coalesce, progressively burying the "bee" structures. The nano-bumps and the material filling the valleys coalesced together seamlessly, suggesting that they share the same composition. The bitumen surface also seemed to grow rougher, with micrometer-scale bumps or pits observed under the optical microscope and in some AFM images (data not shown).

AFM images of bitumen samples after immersion in water at 35 and $50{ }^{\circ} \mathrm{C}$ are shown in Figure 2 and ESI Figures S3 and S4. With even light heating to $35^{\circ} \mathrm{C}$, the aforementioned structural evolution observed at room temperature was dramatically accelerated. The peri phase was entirely concealed after $1 \mathrm{~h}$ in tepid water, and most of the catana phase hills were covered after $4 \mathrm{~h}$. Phase images shown in the insets revealed new lenticular features on the surface that appeared similar to peri phase but independent of the original "bee" structures (see ESI Figure S4 for higher resolution images). These new features grew with immersion time at $35{ }^{\circ} \mathrm{C}$ and showed phase contrast inversion at heavier tapping force (Fig. 2c inset), similar to what was observed when imaging dry peri phase areas [12]. For lack of a better description, these features are referred to as "aqueous peri phase" in the following discussion. AFM images of the bitumen surface upon heating in air show neither nano-bumps nor aqueous peri phase, only distortion of the existing "bee" structures until their disappearance above $60{ }^{\circ} \mathrm{C}[31,32]$. 
AFM images of bitumen samples after immersion in water at 65 and $80{ }^{\circ} \mathrm{C}$ are shown in Figure 3 and ESI Figure S5. With increasing temperature, the wavelength of the "bees" increased until the structures completely disappeared at $65^{\circ} \mathrm{C}$. However, the size of the aqueous peri phase did not follow a consistent trend with temperature. They appeared to fragment into small pieces at $50{ }^{\circ} \mathrm{C}$, but they reappeared larger and more distinct at $65^{\circ} \mathrm{C}$. At $65^{\circ} \mathrm{C}$ and above, the surface morphology was also less dependent on immersion time, and each aqueous peri phase structure contained a single, centrally-located peak or "nucleus." These features are reproducible, but their exact shape and size are strongly dependent on cooling rates. Figure 5 shows images of a bitumen sample soaked in water and cooled slowly from $65^{\circ} \mathrm{C}$ to room temperature over $1.3 \mathrm{~h}$. The aqueous peri phase features after slow cooling appeared larger and more polydisperse in size compared to after rapid cooling (Fig. 3a). Additionally, a handful of them developed miniature catana phase-like regions, which is more evidence that peri phase and aqueous peri phase share similar origins.

\subsection{FTIR analysis}

FTIR spectra given in Figure 5 of a bitumen sample before and after immersion in water for 4 hours at $80^{\circ} \mathrm{C}$ show that water exposure induces changes in chemical composition at the surface of the bitumen. Proposed FTIR peak assignments are listed in ESI Table S1. Measurement of the sample immediately after removal from water and drying with a nitrogen blow gun shows broad absorption peaks at 3392 and $1650 \mathrm{~cm}^{-1}$, indicative of liquid water. Almost all of that water evaporates after an additional 4 hours drying under ambient conditions of $22{ }^{\circ} \mathrm{C}$ and $50 \%$ humidity, demonstrating that this water is mostly residual moisture adsorbed onto the surface and not absorbed into the resin. However, many peaks associated with different non-aqueous polar groups remain even after 24 hours of drying. The most prominent of these peaks include the broad $\mathrm{OH}$ or $\mathrm{NH}$ stretching band $\left(3280 \mathrm{~cm}^{-1}\right)$, the carbonyl stretching vibration $\left(1707 \mathrm{~cm}^{-1}\right)$, and bands attributable to alcohol, ether, ester, sulfoxide, or sulfate groups (1205-1160 $\mathrm{cm}^{-1}$ and $\left.1027 \mathrm{~cm}^{-1}\right)$ [33]. This effect is entirely reversed by reannealing the sample at $150{ }^{\circ} \mathrm{C}$ for $30 \mathrm{~min}$ (red curve), and the spectrum appears almost identical to that for the untreated sample. 
FTIR of a sample soaked in room temperature water for 23 days showed similar chemical shifts (see ESI Figure S6). However, the possibility of microbial contamination of that sample can't be fully discounted (see ESI Figure S7).

The penetration depth of the infrared radiation into the sample is estimated to be no deeper than $3.0 \mu \mathrm{m}$ and is shallower for higher wavenumbers [29]. Therefore, the observed enrichment in polar constituents is probably confined to a thin depth at the surface and suggests either diffusion of polar molecules from the bulk to the water-treated surface or diffusion of nonpolar molecules away from the surface and deeper into the bulk. This molecular diffusion between the bulk and the surface could be driven by water absorbing into the top layer of bitumen and increasing the polarity of the material.[34] Although a significant amount of water could not be detected in the samples after drying, trace absorbed water is difficult to detect by FTIR because the absorption peaks are severely broadened by hydrogen bonding and easily confounded with other bands such as the broad alcohol $\mathrm{OH}$ stretching band around $3280 \mathrm{~cm}^{-1}$ or various carbonyl, amide, amine, or aromatic bands at the edge of the fingerprint region at $1600-1750 \mathrm{~cm}^{-1}$.

Chemical reactions with water are another possible explanation for the FTIR data, but the experimental conditions used in this study are not expected to be adequate to initiate such reactions in sufficient yields. In addition, the observed chemical change is reversible with reannealing which supports the theory that this effect is not the product of irreversible reactions. Reannealing at $150{ }^{\circ} \mathrm{C}$ drives off absorbed water and allows the polar constituents at the surface to diffuse back into the bulk material. Vasconcelos et al. measured water absorption in $1 \mu \mathrm{m}$ thin films of bitumen and reported an increase in water diffusivity with repeated cycles of water exposure and drying [27, 28]. This hysteresis effect was attributed to trace water absorption and bitumen surface restructuring. Diffusion of polar and nonpolar compounds between the bulk and the surface might also increase water diffusivity at the surface, but this mechanism is not possible in thin films. Thus, water absorption and the effects of water treatment may differ between thick and thin film samples. 
How long the moisture-induced chemical change at the bitumen surface persists likely depends on drying conditions. Studies of asphalt mixtures showed a gradual deterioration of mechanical properties with longer water exposure time, but the effects were fully reversible with several days of drying [35]. Properties of asphalt concrete that are more dependent on the nature of the bitumen interface such as adhesion are more likely to feel the lasting effects of water exposure. In fact, water-induced chemical alteration of the surface may point to the role of moisture in the treatment of asphalt mixtures with hydrated lime as an anti-stripping agent $[36,37]$. While polar or ionic chemical groups may be solvated by water and show reduced adhesion when wet, they form very strong intermolecular bonds when dry [34]. The exact effect of moisture-induced chemical alteration of bitumen on the properties of asphalt mixtures is a topic for future research.

\subsection{Effect of high humidity on morphology}

AFM images of a bitumen sample stored under $100 \%$ humidity at room temperature for 2 days are shown in Figure 6 in order to compare the differences between exposure to liquid water and exposure to vapor. Even though the sample was dried with a nitrogen gun before inspection, the optical microscope image showed 5-20 $\mu \mathrm{m}$ circular features on the surface. AFM images showed them to be crater-shaped areas likely where droplets of liquid water condensed on the sample surface. The raised rim of the crater was a result of upward tension exerted by the air-water interface acting on the droplet contact line [26]. The "bee" structures within the craters showed nano-bumps and valley-filling phenomena consistent with liquid water exposure, whereas the areas outside the craters changed little. After 8 days in 100\% humidity, the circles increased slightly in size and number, but no more significant changes were observed (data not shown). The data showed that liquid water exerts a much greater effect on bitumen surface microstructure than water vapor. Accordingly, the possibility of moisture condensation must be taken into consideration for any experiments that involve humid environments or cold samples. 


\subsection{Origin of the nano-bumps}

Recently, the "bee" structures and surrounding peri phase were proposed to be $10 \mathrm{~nm}$ thin lamella of crystallized wax resting on top of a substrate of para phase resin $[12,16]$. While a hydrophobic wax film should normally hinder water diffusion, peri phase areas have been known to exhibit nanoscale dendritic or polycrystalline textures [38-40] that are reminiscent of crystalline polymer structures known as spherulites [41]. In a polycrystalline structure, pinholes may perforate the lamella along the internal grain boundaries and allow water to pass through the film. Thus, a plausible theory is that the nano-bumps are resin from underneath the "bee" film that absorbed water, expanded, and leaked upward through pinhole defects. There is evidence that para phase material is more polar than the peri and catana phases $[39,42]$ and may thus be more likely to absorb a trace amount of water. Water absorption would cause volume expansion and may also decrease the resin viscosity due to solvation of polar and ionic chemical groups, allowing it to flow more readily. This expansion is hypothesized to drive the hydrated resin up the pinholes to the surface, resulting in the nano-bumps. The polar resin would also have a lower surface energy in water than the wax peri phase. Therefore, growth and spreading of the nano-bumps may be driven both by continued water absorption and surface tension forces. Elevated temperature would increase water absorption and reduce resin viscosity further, thus accelerating nano-bump growth as observed (Fig. 2).

While not conclusive, experimental observations are consistent with the above hypothesis. Firstly, the nano-bumps appeared to merge seamlessly with the para phase as the bumps grew with time or temperature under water, suggesting that the two features are the same material (Fig. 1). Additionally, both the nano-bumps and para phase were prone to exhibit tip oscillation artifact or "ringing" (ESI Fig. S4) which is indicative of stronger tip-surface adhesive forces [12, 43, 44]. Stronger adhesion suggests that the material is softer or more polarizable, as might be the case for hydrated resin. Lastly, a thicker wax layer with fewer defects could hinder water absorption and nano-bump formation, and preliminary AFM images of wax-doped bitumen do show dramatically smaller and fewer nano-bumps after water exposure (see ESI Figure S8). 
Most counter arguments for the origin of the nano-bumps cannot be supported based on our observations. The nano-bumps may look like water droplets, but they cannot be liquid because it is nearly impossible to image liquid droplets so clearly by AFM, and water droplets so small are unstable due to rapid evaporation and high surface energy. An alternative hypothesis is that the "bees" are sinking into the para phase due to density changes upon heating. However, AFM of bitumen at elevated temperature in air do not show nano-bumps [31,32], and the "bees" are believed to be made of crystalline wax which is less dense than bitumen or water and shouldn't sink at the temperatures studied. Another theory is that hydrostatic pressure acts to push the "bees" downward while Laplace pressure pushes the para phase out [26], but such pressure forces act on all regions of the surface [34]; there is no plausible reason for hydrostatic or Laplace pressure to selectively exclude or push only on the "bees."

\subsection{Origin of the aqueous peri phase}

The aqueous peri phase has many characteristics in common with the original peri phase including lenticular shape and weaker adhesion to the AFM tip than the para phase. Small areas similar to catana phase are even observed on the slow-cooled sample (Fig. 5). The "bee" structures are believed to be crystallized wax lamellae $[12,16,19,30,45,46]$, but wax crystallization at the bitumen-water interface would seem unlikely given that the water-wax interface is highly unfavorable. However, polar or amphiphilic alkanes and aromatics such as those found in bitumen resin may act as surfactants, segregating to the bitumen surface and orienting themselves so that the hydrophilic polar groups are exposed to the water while the hydrophobic groups interact with non-polar components. Molecular modeling has shown that asphaltene resins can segregate to an oil-water interface and significantly reduce the surface energy [47]. Therefore, the aqueous peri phase may not be composed of pure wax, but it could be wax coated or perhaps even co-crystallized with amphiphilic molecules.

If the aqueous peri phase is mostly wax, then the differences in morphology with respect to temperature and time can also be explained. Crystalline wax in bitumen is known to melt around 50 $60{ }^{\circ} \mathrm{C}[32,48]$. Therefore, aqueous peri phase features are unlikely to be present under water above that 
temperature, but they can appear during cooling. If they only appear during cooling, the features should be independent of water annealing time, which is indeed consistent with observations of the samples annealed at 65 and $80{ }^{\circ} \mathrm{C}$ (Fig. 3). Rapid cooling of a melt phase can also lead to simultaneous nucleation and growth of precipitates, resulting in structures that are smaller and more monodisperse in size and shape than in slow-cooled samples (Fig. 4). Conversely, the aqueous peri phase features observed on $35^{\circ} \mathrm{C}$ samples grow with annealing time (Fig. 2) and are believed to form during warm water exposure. The surface microstructure of the $50{ }^{\circ} \mathrm{C}$ sample may be disordered because the exposure temperature is close to the melting temperature of the wax.

\section{Conclusions}

In asphalt pavement, bituminous binder typically provides a moisture barrier protecting the aggregate skeleton from water damage. However, when binder is exposed to water for an extended period of time, water diffuses into the bitumen film and changes its properties, which can lead to premature pavement deterioration. In an effort to better understand how this deterioration proceeds at the molecular level, this study focused on examining the effects of water exposure on bitumen surface morphology and chemistry in particular. AFM imaging revealed dramatic topological evolution of the bitumen with water exposure at elevated temperature, and FTIR data showed that water exposure resulted in an increased concentration of polar constituents at the bitumen surface. These observed changes in chemical composition and microstructure defy simple explanations, yet are important to consider because they may directly affect how binder properties change with prolonged water exposure. These results point towards complex interactions between water, wax, and surfactants in bitumen. Amphiphilic molecules in particular are candidate additives for their ability to act as surfactants and stabilize water interfaces, which may benefit bitumen performance in aqueous environments. Investigations of the effects of wax and surfactant on bitumen susceptibility to water damage are ongoing and will be the subject of future publications. 


\section{Acknowledgement}

This research is sponsored by the National Science Foundation (Award No: 1150695). The authors are grateful for the support from NSF and the Joint School of Nanoscience and Nanoengineering as well as the State of North Carolina. The authors are also very grateful to Oleg Butyaev, Sergei Magonov, and Marko Surtchev of NT-MDT for useful discussions. The contents of this paper reflect the view of the authors, who are responsible for the facts and the accuracy of the data presented. This paper does not constitute a standard, specification, or regulation.

\section{References}

[1] Caro S, Masad E, Bhasin A, Little DN. Moisture susceptibility of asphalt mixtures, Part 1: mechanisms. International Journal of Pavement Engineering 2008;9:81-98.

[2] Kringos N, Scarpas A, Copeland A, Youtcheff J. Modelling of combined physical-mechanical moistureinduced damage in asphaltic mixes Part 2: moisture susceptibility parameters. International Journal of Pavement Engineering 2008;9:129-51.

[3] Das PK, Baaj H, Kringos N, Tighe S. Coupling of oxidative ageing and moisture damage in asphalt mixtures. Road Materials and Pavement Design 2015;16:265-79.

[4] Sol-Sánchez M, Moreno-Navarro F, García-Travé G, Rubio-Gámez MC. Laboratory study of the longterm climatic deterioration of asphalt mixtures. Construction and Building Materials 2015;88:32-40.

[5] Varveri A, Scarpas A, Collop A, Erkens SMJG. On the combined effect of moisture diffusion and cyclic pore pressure generation in asphalt concrete. Transportation Research Board 93rd Annual Meeting. Washington, USA: Transportation Research Board; 2014.

[6] Banerjee A, de Fortier Smit A, Prozzi JA. The effect of long-term aging on the rheology of warm mix asphalt binders. Fuel 2012;97:603-11.

[7] Merusi F, Caruso A, Roncella R, Giuliani F. Moisture Susceptibility and Stripping Resistance of Asphalt Mixtures Modified with Different Synthetic Waxes. Transportation Research Record: Journal of the Transportation Research Board 2010;2180:110-20.

[8] Tarefder RA, Zaman AM. Nanoscale Evaluation of Moisture Damage in Polymer Modified Asphalts. Journal of Materials in Civil Engineering 2010;22:714-25.

[9] Al-Adham KH, Arifuzzaman MD. Moisture damage evaluation in carbon nanotubes reinforced asphalts. Sustainability, Eco-efficiency, and Conservation in Transportation Infrastructure Asset Management: CRC Press; 2014. p. 103-9.

[10] Yu XK, Burnham NA, Tao MJ. Surface microstructure of bitumen characterized by atomic force microscopy. Advances in Colloid and Interface Science 2015;218:17-33.

[11] Loeber L, Sutton O, Morel J, Valleton JM, Muller G. New direct observations of asphalts and asphalt binders by scanning electron microscopy and atomic force microscopy. Journal of Microscopy-Oxford 1996;182:32-9.

[12] Hung AM, Fini EH. AFM study of asphalt binder "bee" structures: Origin, mechanical fracture, topological evolution, and experimental artifacts. RSC Advances 2015;5:96972-82.

[13] Lyne AL, Wallqvist V, Rutland MW, Claesson P, Birgisson B. Surface wrinkling: the phenomenon causing bees in bitumen. Journal of Materials Science 2013;48:6970-6. 
[14] Nahar SN, Mohajeri M, Schmets AJM, Scarpas A, van de Ven MF, Schitter G. First observation of blend-zone morphology at interface of reclaimed asphalt binder and virgin bitumen. Transportation Research Board 92nd Annual Meeting2013.

[15] Pauli T, Grimes W, Beiswenger J, Schmets AJM. Surface Structuring of Wax in Complex Media. Journal of Materials in Civil Engineering 2015;27:C4014001.

[16] Pahlavan F, Mousavi M, Hung A, Fini EH. Investigating molecular interactions and surface morphology of wax-doped asphaltenes. Physical Chemistry Chemical Physics 2016;18:8840-54.

[17] Menapace I, Masad E, Bhasin A, Little D. Microstructural properties of warm mix asphalt before and after laboratory-simulated long-term ageing. Road Materials and Pavement Design 2015;16:2-20.

[18] Wu S-p, Pang L, Mo L-t, Chen Y-c, Zhu G-j. Influence of aging on the evolution of structure, morphology and rheology of base and SBS modified bitumen. Construction and Building Materials 2009;23:1005-10.

[19] Yu XK, Zaumanis M, dos Santos S, Poulikakos LD. Rheological, microscopic, and chemical characterization of the rejuvenating effect on asphalt binders. Fuel 2014;135:162-71.

[20] Huang S-C, Pauli AT. Particle Size Effect of Crumb Rubber on Rheology and Morphology of Asphalt Binders with Long-term Aging. Road Materials and Pavement Design 2008;9:73-95.

[21] Zhang HL, Yu JY, Feng ZG, Xue LH, Wu SP. Effect of aging on the morphology of bitumen by atomic force microscopy. Journal of Microscopy 2012;246:11-9.

[22] Fini EH, Oldham D, Parast M. An Empirical Examination of the Moderating Impact of Maximum Bee Length on the Relationship between Stiffness and Fracture Energy. Peterson Asphalt Research Conference. Laramie, WyomingJuly 13-15, 2015.

[23] Allen RG, Little DN, Bhasin A. Structural Characterization of Micromechanical Properties in Asphalt Using Atomic Force Microscopy. Journal of Materials in Civil Engineering 2012;24:1317-27.

[24] Das PK, Kringos N, Birgisson B. Microscale investigation of thin film surface ageing of bitumen. Journal of Microscopy 2014;254:95-107.

[25] Poulikakos LD, Santos Sd, Bueno M, Kuentzel S, Hugener M, Partl MN. Influence of short and long term aging on chemical, microstructural and macro-mechanical properties of recycled asphalt mixtures. Construction and Building Materials 2014;51:414-23.

[26] dos Santos S, Partl MN, Poulikakos LD. Newly observed effects of water on the microstructures of bitumen surface. Construction and Building Materials 2014;71:618-27.

[27] Vasconcelos KL, Bhasin A, Little DN. History dependence of water diffusion in asphalt binders. International Journal of Pavement Engineering 2011;12:497-506.

[28] Vasconcelos K, Bhasin A, Little D. Measurement of Water Diffusion in Asphalt Binders Using Fourier Transform Infrared-Attenuated Total Reflectance. Transportation Research Record: Journal of the Transportation Research Board 2010;2179:29-38.

[29] Griffiths PR, de Haseth JA. Fourier Transform Infrared Spectrometry. 2nd ed. New York: WileyInterscience, John Wiley and Sons, Inc.; 2007.

[30] Masson JF, Leblond V, Margeson J. Bitumen morphologies by phase-detection atomic force microscopy. Journal of Microscopy-Oxford 2006;221:17-29.

[31] De Moraes MB, Pereira RB, Simao RA, Leite LFM. High temperature AFM study of CAP 30/45 pen grade bitumen. Journal of Microscopy 2010;239:46-53.

[32] Soenen H, Besamusca J, Fischer HR, Poulikakos LD, Planche J-P, Das PK, et al. Laboratory investigation of bitumen based on round robin DSC and AFM tests. Mater Struct 2014;47:1205-20.

[33] Lambert JB, Gronert S, Shurvell HF, Lightner DA. Organic Structural Spectroscopy. 2nd ed. New York: Prentice Hall; 2011.

[34] Israelachvili JN. Intermolecular and Surface Forces. 3rd ed. San Diego: Academic Press; 2011.

[35] Apeagyei AK, Grenfell JRA, Airey GD. Observation of reversible moisture damage in asphalt mixtures. Construction and Building Materials 2014;60:73-80. 
[36] Kim Y-R, Pinto I, Park S-W. Experimental evaluation of anti-stripping additives in bituminous mixtures through multiple scale laboratory test results. Construction and Building Materials 2012;29:386-93.

[37] Lesueur D, Petit J, Ritter H-J. The mechanisms of hydrated lime modification of asphalt mixtures: a state-of-the-art review. Road Materials and Pavement Design 2013;14:1-16.

[38] Fischer HR, Dillingh EC, Hermse CGM. On the microstructure of bituminous binders. Road Materials and Pavement Design 2013;15:1-15.

[39] Magonov S, Alexander J, Surtchev M, Hung AM, Fini EH. Compositional mapping of bitumen using local electrostatic force interactions in atomic force microscopy. Journal of Microscopy 2016.

[40] Fischer HR, Dillingh B. Response of the microstructure of bitumen upon stress-damage initiation and recovery. Road Materials and Pavement Design 2015;16:31-45.

[41] Gránásy L, Pusztai T, Tegze G, Warren JA, Douglas JF. Growth and form of spherulites. Physical Review E 2005;72:011605.

[42] Allen RG, Little DN, Bhasin A, Glover CJ. The effects of chemical composition on asphalt microstructure and their association to pavement performance. International Journal of Pavement Engineering 2014;15:9-22.

[43] Yu XK, Burnham NA, Mallick RB, Tao MJ. A systematic AFM-based method to measure adhesion differences between micron-sized domains in asphalt binders. Fuel 2013;113:443-7.

[44] Strus MC, Raman A, Han CS, Nguyen CV. Imaging artefacts in atomic force microscopy with carbon nanotube tips. Nanotechnology 2005;16:2482.

[45] Jäger A, Lackner R, Eisenmenger-Sittner C, Blab R. Identification of four material phases in bitumen by atomic force microscopy. Road Materials and Pavement Design 2004;5:9-24.

[46] Zhang HL, Wang HC, Yu JY. Effect of aging on morphology of organo-montmorillonite modified bitumen by atomic force microscopy. Journal of Microscopy 2011;242:37-45.

[47] Mikami Y, Liang Y, Matsuoka T, Boek ES. Molecular Dynamics Simulations of Asphaltenes at the OilWater Interface: From Nanoaggregation to Thin-Film Formation. Energy \& Fuels 2013;27:1838-45.

[48] Das PK, Kringos N, Wallqvist V, Birgisson B. Micromechanical investigation of phase separation in bitumen by combining atomic force microscopy with differential scanning calorimetry results. Road Materials and Pavement Design 2013;14:25-37. 

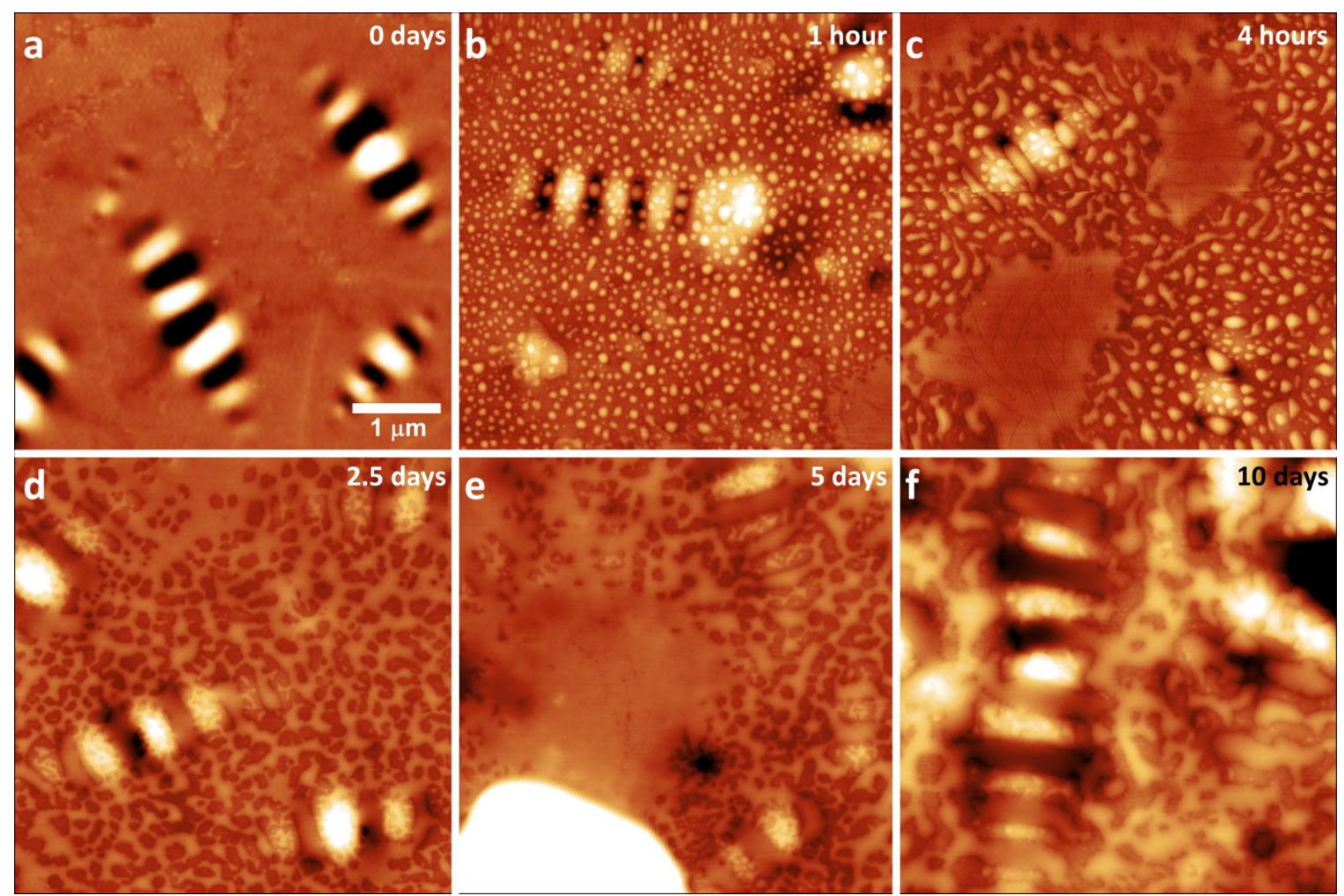

Figure 1. AFM height images of bitumen samples (a) before and (b-f) after soaking in water at room temperature $\left(22{ }^{\circ} \mathrm{C}\right)$ for one hour to 10 days. Scale bar applies to all images. The false color height scale is $35 \mathrm{~nm}$ for (a-c) and $50 \mathrm{~nm}$ for $(\mathrm{d}-\mathrm{f})$.

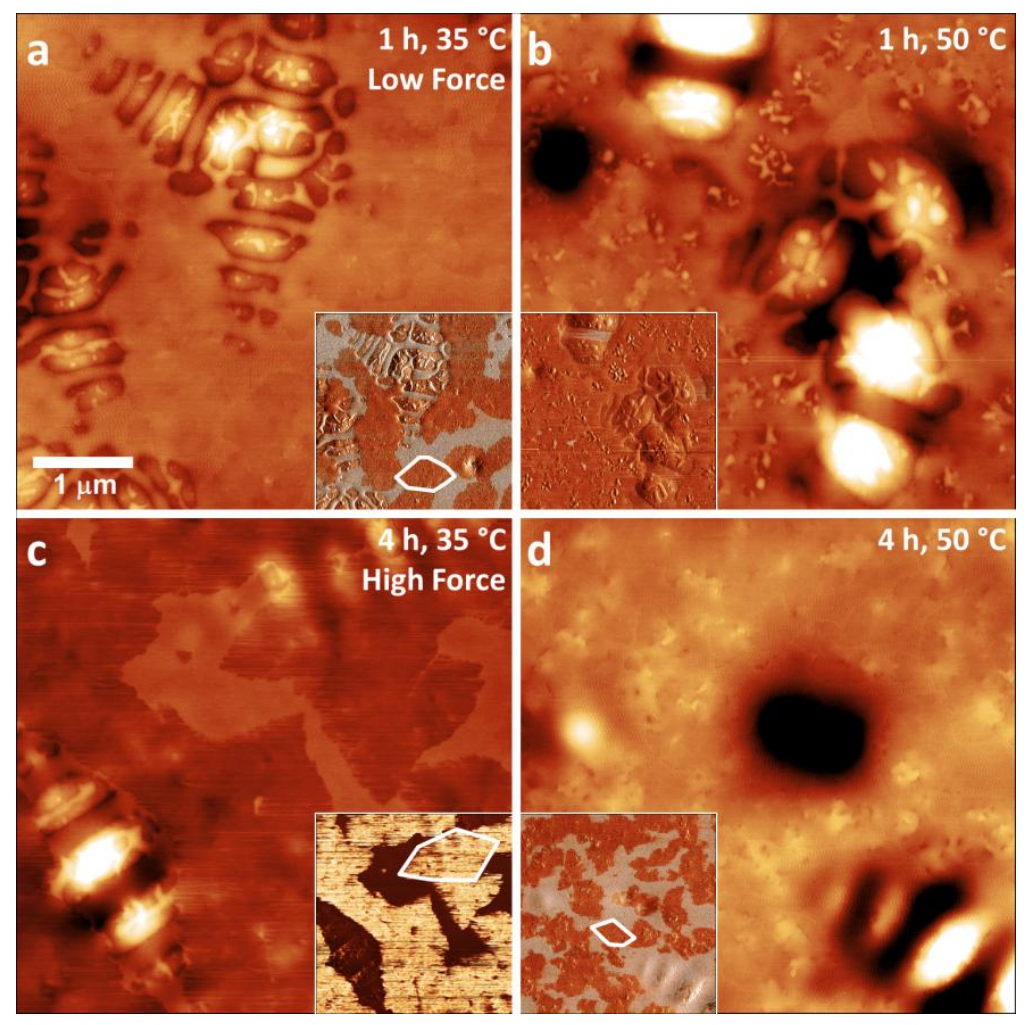


Figure 2. AFM images of bitumen samples immersed in water for $(\mathrm{a}, \mathrm{b}) 1 \mathrm{~h}$ or $(\mathrm{c}, \mathrm{d}) 4 \mathrm{~h}$ at $(\mathrm{a}, \mathrm{c}) 35^{\circ} \mathrm{C}$ or (b, d) $50{ }^{\circ} \mathrm{C}$. False color height scale is $35 \mathrm{~nm}$ and scale bar applies to all images. Insets give the corresponding phase images that reveal the aqueous peri phase (white outlined examples). (c) Under high tapping force the aqueous peri phase is more visible and phase contrast is inverted.

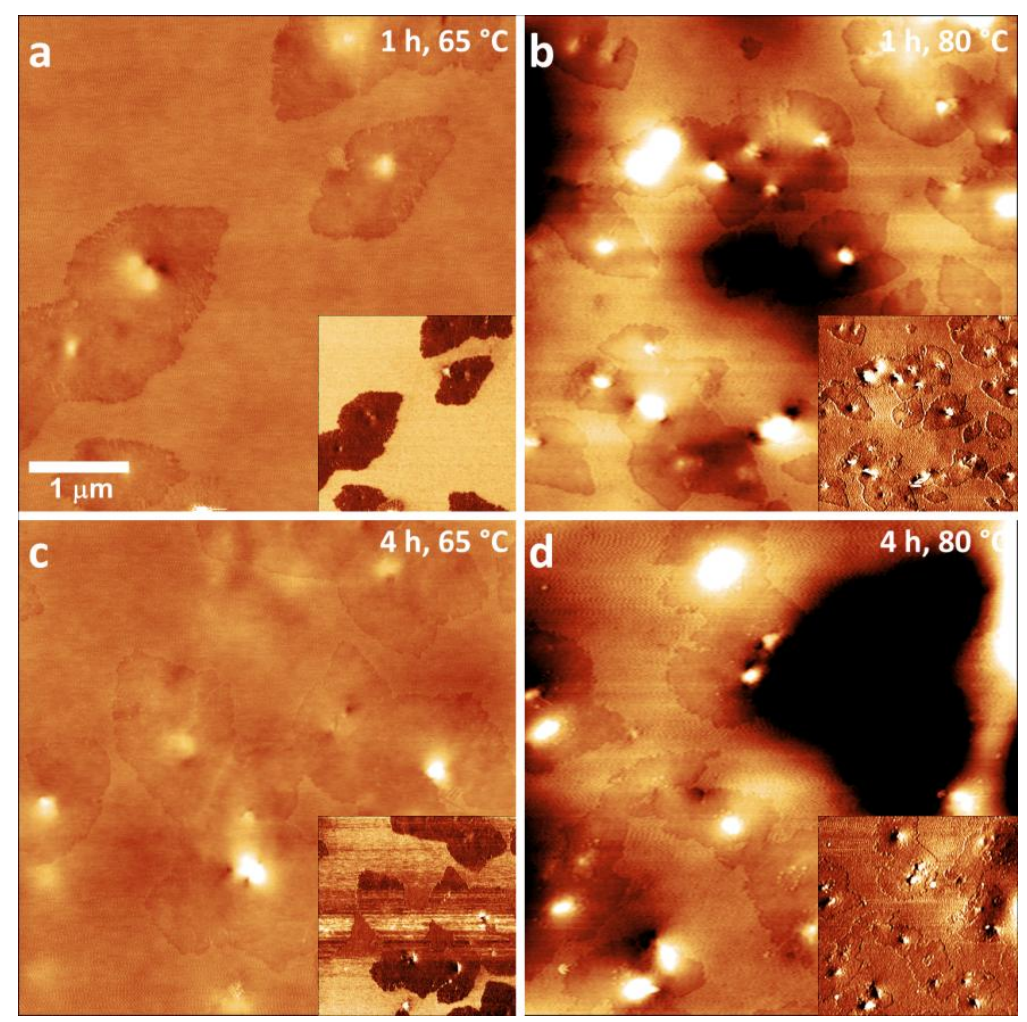

Figure 3. AFM height images of bitumen samples immersed in water for (a, b) $1 \mathrm{~h}$ or (c, d) $4 \mathrm{~h}$ at (a, c) $65^{\circ} \mathrm{C}$ or (b, d) $80{ }^{\circ} \mathrm{C}$. False color height scale is $20 \mathrm{~nm}$ and scale bar applies to all images. Insets show the corresponding phase images. The aqueous peri phase show little change between $1 \mathrm{~h}$ and $4 \mathrm{~h}$ water immersion.

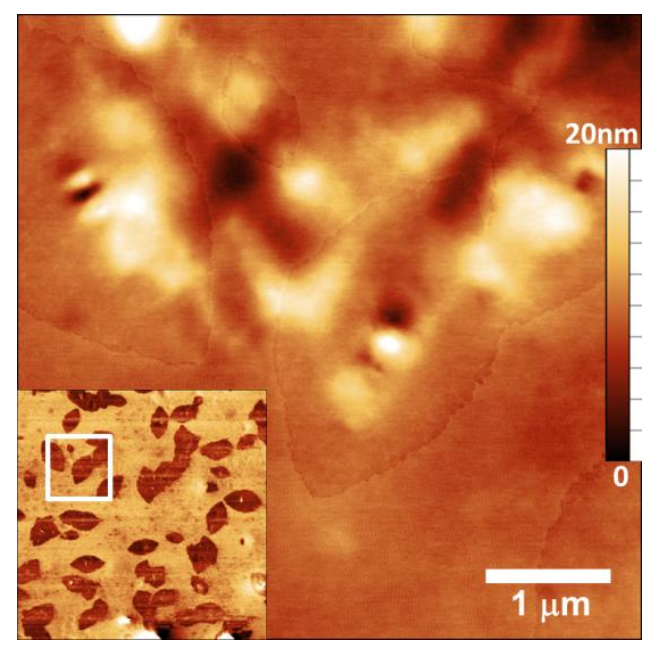

Figure 4. AFM image of a bitumen sample immersed in water at $65^{\circ} \mathrm{C}$ for $1 \mathrm{~h}$ and cooled slowly to room temperature over $1.3 \mathrm{~h}$ showing large aqueous peri phase domains. Inset is a phase image of the wider area $(20 \mu \mathrm{m})$. 


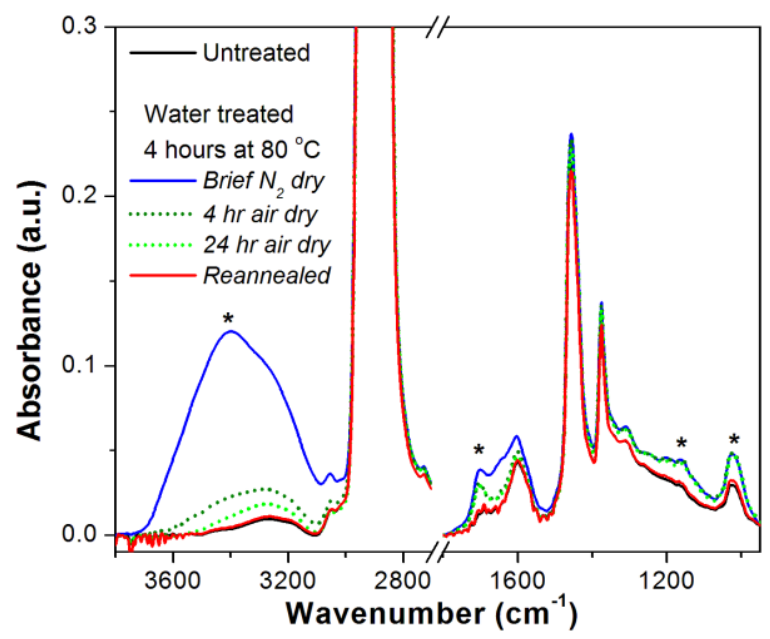

Figure 5. FTIR spectra of a bitumen sample before and after annealing in $80{ }^{\circ} \mathrm{C}$ water followed by drying and reannealing at $150{ }^{\circ} \mathrm{C}$. Asterisks highlight major changes in the spectra due to water treatment. Spectra are normalized to the peak at $2920 \mathrm{~cm}^{-1}\left(\mathrm{CH}_{2}\right.$ antisymmetric stretch).

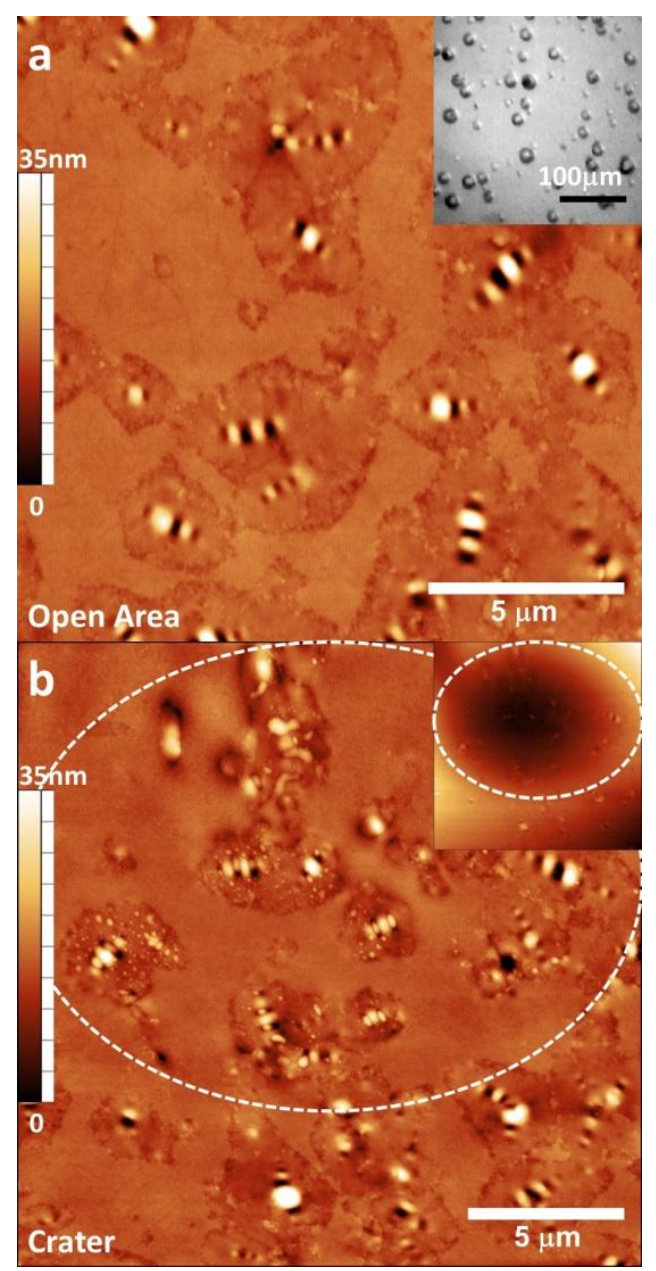

Figure 6. (a) An optical microscope image of a bitumen sample after 2 days exposure to $100 \%$ humidity (inset) reveals circular features roughly $5-20 \mu \mathrm{m}$ in diameter. AFM image of an area between the circles show little change to the "bee" structures. (b) AFM image of a circle reveals it to be a bowl-shaped crater (dashed oval) within which the "bees" show nano-bumps indicative of liquid water exposure. The image 
(b) and inset are the same picture with and without extra flattening, respectively (inset false color height scale is $220 \mathrm{~nm}$ ). 